\title{
Bladder Verrucous Carcinoma
}

National Cancer Institute

\section{Source}

National Cancer Institute. Bladder Verrucous Carcinoma. NCI Thesaurus. Code C39832.

A rare variant of well differentiated squamous cell carcinoma, usually associated with bladder schistosomiasis. 